\title{
Deficit in depth perception of 90-day-old dark-reared rats'
}

\author{
RICHARD D. WALK AND ELIZABETH K. BOND \\ GEORGE WASHINGTON UNIVERSITY
}

Dark- and light-reared 90-day-old hooded rats were tested on the visual cliff. Dark-reared animals preferred the shallow side at 10 in., but not at $4 \mathrm{in}$, of visual depth. Light-reared controls preferred the shallow at both depths. The results show an impairment in motion discrimination from prolonged rearing without light even though gross depth discrimination remained intact.

In 1934 Lashley and Russell showed that rats reared in the dark for three months exert more force in jumping for distant pedestals than for near ones. They inferred that depth perception in the rat is innate. Walk, Gibson, \& Tighe (1957) used a visual cliff apparatus to corroborate their findings, and subsequent research has replicated the Walk et al study under different conditions (Nealey \& Edwards, 1960; Walk \& Gibson, 1961; Carr \& McGuigan, 1965).

Is this depth perception of dark-reared animals as good as that of the light-reared? Evidence, so far, indicates that it is, but this paper will show that it is not.

The visual cliff apparatus has a center board that bisects a piece of glass. Directly under one-half of the glass, the "shallow" side, is a textured pattern; the textured surface is some distance below the glass on the other side, the "deep" side. For an animal standing on the center board motion parallax differentiates the two sides; when the animal moves its head the distant and close patterns appear to move at different rates, and it descends to the "safe" surface.

The original visual cliff used a $53 \mathrm{in}$. visual depth. Subsequent research has shown that a visual depth of $10 \mathrm{in.}$ is sufficient. If the deep visual surface were brought closer to the glass, a point of relative indifference should be reached. Booher (1967) constructed an apparatus that allowed the deep side to vary continuously in its approach toward the shallow side. The $75 \%$ preference point for the hooded rat was at 3 in. of visual depth; at greater visual depth, over $80 \%$ of the descents were to the shallow side. From $1 / 2$ in. to $1-1 / 2$ in. of differential visual depth the preference for the shallow side was about at a chance level with about $60 \%$ choice of the shallow at 2 to $2-1 / 2$ in.

Method

The present study used Booher's apparatus. The patterns were lighted from below to eliminate any shadows as the deep side was brought toward the shallow side. An $18 \times 30$ in. wooden box (inside dimensions) with sides $15-1 / 2$ in. high and a floor of glass was bisected by a center board 4 in. high, 4 in. wide, and 18 in. long.

Below the glass on one side of the center board (the shallow side) was a 14-1/2 $\times 21$ in. box 12 in. deep with two standard $15-W$ bulbs mounted on its floor. Plexiglas W-247 was on top of the box to diffuse the light, and a cloth pattern of 1 in. checks was on top of the plexiglas. The box was held in grooves and could slide from one side to another to control for position or environmental preferences. The deep illuminance came from a 5 ft long $x 3 \mathrm{ft}$ wide $x 1 \mathrm{ft}$ deep box of plywood on rollers, with 15 15-W bulbs in it, a plexiglas top, and 1 in. checks.

The frame for the box that enclosed the visual cliff consisted of two $7 \mathrm{ft}$ long boards, supported by four legs that rested on the floor and two $30 \mathrm{in.} \mathrm{boards}$ perpendicular to them. The middle $18 \mathrm{in}$. of this frame made up the shorter sides of the cliff (parallel to the center board) while the two $30 \mathrm{in}$. boards formed the longer sides. Wooden blocks were placed under the legs of the apparatus to raise the visual cliff to the varlable visual depths used in the experiment.

Our pilot-tested animals discriminated depth well at 10 in. visual depth on the deep side but not at 3 in., Booher's 75\% point for shallow preference. At 4 in. a definite shallow preference appeared.

Hooded rats were reared in the dark for 90 days except for a brief interval (less than $10 \mathrm{~min}$ ) at 40 days of age to remove the mother and place males and females in separate cages. Experimental animals were matched with adult light-reared controls, most of whom were split-litter controls. Dark-reared animals were removed in groups of four from the dark to be tested. The light-reared were also tested in groups of four. Each animal was tested twice. The animal was placed at one end of the center board and allowed $3 \mathrm{~min}$ to descend. Visual depth was changed after the entire group of four had been run. Balancing procedures assured that no bias was introduced by position of shallow side, first visual depth tested, or end of center board on which each $S$ was placed. The glass was cleaned after each S's descent.

Resulis

The results, presented in Table 1 , show that the dark-reared animals discriminate depth at $10 \mathrm{in.}$ but not at 4 in. The depth discrimination of the lightreared is approximately the same at both visual depths. Fisher's exact test applied to the first re- 
Table 1. Depth Perception of Dark- and Light-reared Rats with Visual Depth Varied.

\begin{tabular}{|c|c|c|c|c|c|}
\hline Depth & \multirow[b]{2}{*}{ Descent } & \multicolumn{2}{|c|}{$\begin{array}{l}\text { Light-reared } \\
(\mathrm{N}=24)\end{array}$} & \multicolumn{2}{|c|}{$\begin{array}{c}\text { Dark-reared } \\
(\mathrm{N}=20)\end{array}$} \\
\hline Visual & & Response & $\%$ & Response & $\%$ \\
\hline \multirow{3}{*}{4 in. } & Shallow side & 10 & 71 & 1 & 11 \\
\hline & Deep side & 4 & 29 & 8 & 89 \\
\hline & No descent & 10 & - & 11 & - \\
\hline \multirow{3}{*}{$10 \mathrm{in.}$} & Shallow side & 9 & 75 & 5 & 83 \\
\hline & Deep side & 3 & 25 & 1 & 17 \\
\hline & No descent & 12 & - & 14 & - \\
\hline
\end{tabular}

Note: Percentage figured only on actual descents.

sponses only of the dark-reared animals (to avoid an inflated $N)$ shows a significant difference $(p<.05)$ for the dark-reared on the 4 in. as compared to the 10 in. visual depth. The responses of the dark-reared also differ significantly from those of the light-reared to the 4 in. depth $(p<.02)$. Light- and dark-reared do not differ significantly at the $10 \mathrm{in.} \mathrm{depth;} \mathrm{both}$ choose the shallow about $80 \%$ of the time.

Table 1 also shows a definite preference for the deep side in the dark-reared animals at the 4 in. depth. We have no explanation for this and must assume, tentatively, that it is a chance finding since illumination of the two sides was equal and other factors were controlled.

After two weeks in the light, the dark-reared and some of the light-reared were run again. A method to induce more descents without frightening the animals was devised by one of us (EKB). A long narrow pan of cold water was placed on a lower center board with a total descent distance to the glass about the same (3 in.). The dark-reared made six shallow descents and six deep descents at 4 in. visual depth along with eight no descents. At $8-1 / 2$ in. visual depth there were 13 shallow and 2 deep descents and five no descents. The light-reared $(\mathrm{N}=13)$ made 10 shallow and three deep descents at 4 in. and seven shallow, four deep, and two no descents at $8-1 / 2$ in. of visual depth. Ordęr of testing was counterbalanced. The results after two weeks in the light corroborate the findings secured on first emergence from the dark: impairment in finer motion discrimination but none in grosser discrimination.

\section{Discussion}

These results from sensory deprivation are related to research on the normal development of depth perception. Human infants less then 10 months of age are more likely to be coaxed across the deep side of the visual cliff than are 10-12-month-old infants. The difference appears for lesser visual depths (10 or 20 in.), but not for greater (40 in.) ones (Walk, 1966). Ames \& Silfen (1965) have shown the development of preferences for moving patterns in young infants, seven to 24 weeks old. The older infants showed better discrimination of motion than did the younger ones. Both experiments would appear to show the development of sensitivity to motion in the infant.

The present experiment cannot determine whether dark-rearing inhibits the development of motion discrimination in the rat or whether dark-rearing atrophies the innate mechanisms. The technique employed does, however, lend itself to solution of this problem.

\section{References}

AMES, E. W., \& SILFEN, C. K. Methodological issues in the study of age differences in infants' attention to stimuli varying in movement and complexity. Paper read at Society for Research in Child Development, Minneapolis, Minnesota, March 25, 1965.

BOOHER, H. R. Differential visual depth perception threshold in the hooded rat. Unpublished M.A. thesis, George Washington University, Washington, D.C., 1967.

CARR, W. J., \& McGUIGAN, D. I. The stimulus basis and modification of visual cliff performance in the rat. Anim. Behav., 1965, 13, 25-29.

LASHLEY, K. S., \& RUSSELL, J. T. The mechanism of vision XI. A preliminary test of innate organization. J. genet. Psychol., 1934, 45, 136-144.

NEALEY, S. M., \& EDWARDS, B. J. "Depth perception" in rats without pattern vision experience. J. comp. physiol. Psychol., 1960, 53, 468-469.

WALK, R. D. The development of depth perception in animals and human infants. Child Devel. Monogr., 1966, 31 (107), 82-108.

WALK, R. D., \& GIBSON, E. J. A comparative and analytical study of visual depth perception. Psychol. Monogr., 1961, 75 (519), 1-44.

WALK, R. D., GIBSON, E. J., \& TIGHE, T. J. Behavior of light- and dark-reared rats on a visual cliff. Science, 1957, 126, 80-81.

Note

1. Supported by NIH Grant HD-203 and by NSF grants. 